\title{
Editorial Note: Basilar Thrombosis, a Diagnosis not to be Missed
}

\section{Herbert Alejandro Manosalva Alzate*}

Fellowship in Stroke Neurology, Movement Disorders and Neurogenetics, Division of Neurology, Department of Medicine, Sunnybrook Hospital - University of Toronto, Toronto, Canada

*Corresponding Author: Herbert Alejandro Manosalva Alzate, Fellowship in Stroke Neurology, Movement Disorders and Neurogenetics, Division of Neurology, Department of Medicine, Sunnybrook Hospital - University of Toronto, Toronto, Canada.

Received: June 17, 2019; Published: July 01, 2019

DOI: $10.31080 /$ ASNE.2019.02.0075

It is well known that stroke related to basilar thrombosis carries out the highest risk of mortality among any other type of brain arterial occlusion, even going up to $96 \%$ of mortality. Current therapies including intravenous thrombolysis and mechanical endovascular thrombectomy could decrease that risk down to $76 \%$ and $39 \%$ respectively [1]. Its diagnosis is top priority for any emergency or vascular service, particularly in young adults due to the high emotional and economy burden that may impose to families. These are key elements to consider when approaching these patients.

- $\quad$ Acute headache: thunderclap headache in a young adult [2] (acute onset of severe headache 10/10 reaching its maximum within a minute and lasting not shorter than 5 minutes) is associated with vertebral artery dissection, the most common type of stroke etiology in young adults [3].

- Involuntary movement with decreased level of consciousness (LOC) mimicking a seizure. Jerky movements, clonic proximal and distal upper limb movements, extending tonic posturing movements particularly in lower limbs have been described associated to basilar thrombosis without cortical activity on EEG, but proven basilar thrombosis on angiogram/CTA/MRA studies. Frequently the ischemic lesion was found at the level of the basis pontis and tegmentum [4].

- Get familiar with ocular brainstem stroke signs such as inter nuclear ophthalmoparesis (INO) and ocular bobbing (repetitive involuntary vertical eye movements in a patient in coma starting from a midline neutral position with a fast downward vertical gaze phase, followed by a slow upward phase up to the midline neutral position). This last involuntary ocular movement can be seen in unconscious patients after massive pons stroke. Clinical evolution towards a lock in syndrome is frequently seen if patient survives [5].

\section{Bibliography}

1. Mohlenbruch M., et al. "Mechanical thrombectomy with stent retrievers in acute Basilar artery occlusion". AJNR American Journal of Neuroradiology 35 (2014): 959-964.

2. Ducros A and Bousser M. "Thunderclap headache”. BMJ 345 (2012): e8557.

3. Saeed AB., et al. "Vertebral artery dissection: warning symptoms, clinical features and prognosis in 26 patients". Canadian Journal of Neurological Sciences 27 (2000): 292-296.

4. Saposnik G and Caplan L. "Convulsive-like movements in brainstem stroke". Archives of Neurology 58 (2001): 654-657.

5. Daroff R and Waldman A. "Ocular bobbing”. Journal of Neurology, Neurosurgery, and Psychiatry 28 (1965): 375-377.

\section{Volume 2 Issue 8 August 2019 \\ (C) All rights are reserved by Herbert Alejandro Manosalva Alzate.}

